\title{
EVALUATION OF ASTER IMAGES FOR CHARACTERIZATION AND MAPPING OF AMETHYST MINING RESIDUES
}

\author{
P. R. Markoski ${ }^{\text {a }}$ S. B. A. Rolim ${ }^{\mathrm{a}}$ \\ ${ }^{a}$ CEPSRM/UFRGS, Centro Estadual De Pesquisas em Sensoriamento Remoto e Meteorologia - \\ Universidade Federal Do Rio Grande do Sul - Brazil (00137854, silvia.rolim)@ufrgs.br
}

Commission VII, WG VII/4

KEY WORDS: SAM, Classification methods, MaxVer, ASTER, Spectral analysis

\begin{abstract}
:
The objective of this work was to evaluate the potential of Advanced Spaceborne Thermal Emission and Reflection Radiometer (ASTER), subsystems VNIR (Visible and Near Infrared) and SWIR (Short Wave Infrared) images, for discrimination and mapping of amethyst mining residues (basalt) in the Ametista do Sul Region, Rio Grande do Sul State, Brazil. This region provides the most part of amethyst mining of the World. The basalt is extracted during the mining process and deposited outside the mine. As a result, mounts of residues (basalt) rise up. These mounts are many times smaller than ASTER pixel size (VNIR - 15 meters and SWIR - 30 meters). Thus, the pixel composition becomes a mixing of various materials, hampering its identification and mapping. Trying to solve this problem, multispectral algorithm Maximum Likelihood (MaxVer) and the hyperspectral technique SAM (Spectral Angle Mapper) were used in this work. Images from ASTER subsystems VNIR and SWIR were used to perform the classifications. SAM technique produced better results than MaxVer algorithm. The main error found by the techniques was the mixing between "shadow" and "mining residues/basalt" classes. With the SAM technique the confusion decreased because it employed the basalt spectral curve as a reference, while the multispectral techniques employed pixels groups that could have spectral mixture with other targets. The results showed that in tropical terrains as the study area, ASTER data can be efficacious for the characterization of mining residues.
\end{abstract}

\section{INTRODUCTION}

The Remote Sensing and auxiliary computing techniques are important tools used for the identification, geological mapping and mineral exploration. These tools aim to spectral discrimination of targets. To accomplish this discrimination is important to know about the spectral behavior through the observation of diagnostic features that express the physical and chemical composition of each element on study. One way to perform this type of study is using orbital sensors that allow study on a large spatial scale.

On the other hand, this approach is subject to direct influence of the atmosphere, the gases and aerosols, reducing and changing the behavior of the electromagnetic radiation captured by the sensor, generating absorption/scattering effects. Among the gases that most contribute to these effects is the water vapor which constitutes about $2 / 3$ of the atmosphere and shows absorption features around $0.94 \mu \mathrm{m}, 1.14 \mu \mathrm{m}, 1.38 \mu \mathrm{m}$ and 1.88 $\mu \mathrm{m}$; oxygen $(\mathrm{O} 2)$ (features between 0.60 and $0.30 \mu \mathrm{m}$ ), Carbon Dioxide (CO2) (features around $1.96 \mu \mathrm{m}, 2.01 \mu \mathrm{m}, 2.08 \mu \mathrm{m}$ ), methane (CH4) (feature around 2:35 $\mu \mathrm{m}$ ) and Ozone (O3) (feature next to the $0.60 \mu \mathrm{m}$ ) (Gao et al., 1993).

Spectral nature processes are largely used for the treatment of hyperspectral data, through techniques that reduce the data dimensionality, correct the redundancies and identify extreme members (endmembers). Such techniques are currently being used also for multispectral data sensors, with satisfactory results, such as those by Vicente (2007), Linn (2008) and Breunif (2008).
The traditional classification methods, such as MaxVer, Minimum Distance, and others, are applied by prior knowledge of the targets by collecting training samples. Spectral classification methods are also applied by a prior knowledge of the targets, but implying a supervised classification based on sampling and analysis of spectral signatures and their comparison with the image pixels. Such signatures can be obtained by collecting endmembers directly on the image, measured in laboratories or field, using a spectroradiometer or using a spectral library. The classification by spectral analysis allows discretize each pixel by its correlation with the material that composes it (spectrum) in a direct way, establishing location and, sometimes, sub-pixel composition (Vicente, 2007).

In this context, this study aims to evaluate the use of ASTER sensor images, along techniques of remote sensing and digital image processing for the mapping and identification of basalt residues extracted from amethyst mines in the Ametista do Sul city, North of Rio Grande do Sul State, Brazil (Figure 1).

The basalt rock is very dark, compact, sometimes with cavities and some crystals developed on the solid mass formed by minerals rich in iron and magnesium. It is a basic igneous rock composed mainly of fine grains of plagioclase feldspar enriched with calcium and pyroxene. There may also be present other minerals such as olivine, magnetite and apatite. It is the most common lava. It was crystallized from magma at the surface or near the Earth's surface. It quickly cools and the minerals do not grow much. Thus, difficult to observe them with the naked eye. 


\section{METHODS}

In this paper we evaluated two classification techniques: algorithm MAXVER and the SAM (Spectral Angle Mapper) technique. The reason why we chose these two techniques is the fact that they have been successfully used in other studies of soil and rocks. Here are introduced the theories that explain these two techniques and processing.

\subsection{MaxVer algorithm}

MaxVer or Maximum Likelihood is a statistical classification method that considers the weighting of the distances between averages of digital classes values using statistical parameters. To be accurate enough, MaxVer needs a great number of "pixels" for each training set (greater than 30). The training sets define the classes scatter diagram and their probability distributions, considering the normal probability distribution for each training class. The classification limits are defined from points of same classification probability for all classes. Below is showed the equation that defines the MAxVer algorithm:

$$
\begin{gathered}
g_{j}(x)=-\frac{1}{2}\left(x-m_{j}\right)^{t} \sum_{j}^{-1}\left(x-m_{j}\right)-\frac{1}{2} \ln \left|\sum_{j}\right| \\
+\ln P\left(\omega_{j}\right)
\end{gathered}
$$

Where: $\mathrm{m}=$ Vector of averages

$\Sigma=$ Covariance matrix

$\omega=$ Occurrence probability of each class

\subsection{Minimum Noise Fraction (MNF)}

Hyperspectral and multispectral data are, no doubt, a great source of information. However, there are three factors that should be considered: (a) the high degree of correlation between bands due to the high number of narrow contiguous bands, resulting in redundant information (in hyperspectral case), (b) susceptibility to noise interference, which complicates the materials identification and quantification, and (c) the computational requirements for subsequent processing. In order to correct such problems, Green et al (1998) proposed a methodology - MNF (Minimum Noise Fraction), based on PCA (Principal Component Analysis). The MNF transformation combines both procedures for the segregation of the noise component as well as maximizing the variance of the data. In other words, the goal is to condense the targets spectral information contained in many specter electromagnetic bands in a reduced number of bands transformed, without information lost, which makes it an important phase in the digital processing for endmembers identification in an image. These transformations are performed pixel by pixel and not depend the spatial location of the data (Linn, 2008, citing Junior Carvalho et al, 2003).

Essentially, the MNF transformation follows two sequential transformations. The first is based on a noise estimated covariance matrix to remove interband correlation and re-scale the noise. This transformation results in a set of bands characterized by equivalent variance. The second transformation consist in a standard transform by PCA (Principal Component Analysis), resulting in a new set of bands that is ordered according to the eigenvalues, that express the bands variance. The ascending order of the components results in increased noise level, indicated by the smaller variance.
Data from MNF transformation can be divided into two groups: the first group associated with the largest eigenvalues (largest variance) and low-noise images, presenting images spatially coherent, and a second group, associated with higher order MNF bands (lower variance), with noisy images with eigenvalues close to unity (ENVI, 2000). The second group of MNF components is dispensed and the MNF bands of the first group, which represent the dimensionality of the data, are selected for subsequent processing.

\subsection{Pixel Purity Index (PPI)}

Boardman et al. (1995) developed the PPI (Pixel Purity Index) to select Endmembers on images through the determination of an n-dimensional simplex which fits with the image data. The pixels are processed and projected onto a random unit vector where the most extreme pixels in each projection are recorded, as well as the total number of times it occurs. Finally, a PPI image is generated in which the gray value of each pixel corresponds to the number of times each pixel was recorded as extreme in some projection (So higher the value of the pixel in the image PPI, greater its degree of purity ).

Thus, from the PPI image, can provide new values for the cut point using a slice technique, which allows a better selection of endmembers. It is observed at increasing the value PPI cutting, areas of pure pixels become more restricted. This is very useful for field investigation to determine the location of pure pixels.

\subsection{Spectral Angle Mapper (SAM)}

The SAM technique (Spectral Angle Mapper) (Kruse et al., 1993) is a tool that allows rapid mapping of the similarity between the spectrum of a pixel and a reference material. The reference spectrum can be both laboratory and field, a spectral library or extracted from the image. This method assumes that the image data was converted to surface reflectance. The algorithm determines the spectral similarity between two spectra calculating the angle formed between them, treating them as vectors in a space of dimensionality corresponding to the number of bands (nb) (Equatio 2)

$\emptyset=\operatorname{Cos}^{-1}\left[\frac{\sum_{i=1}^{n} t_{i} r_{i}}{\sqrt{\sum_{i=1}^{n} t_{i}^{2} \sum_{i=1} r_{i}^{2}}}\right]$

Where: $n=$ number of spectral band

$\mathrm{t}=$ reflectance of the actual spectrum

$\mathrm{r}=$ reflectance of the reference spectrum

This similarity measure is insensitive to gain factors because the angle between two vectors is invariant with respect to the lengths of vectors. Laboratory spectra can be directly compared to pixels surface reflectance spectra, which inherently have a gain factor related to unknown illumination effects due to topography (Kruse et al. 1993). As a result, we obtain a classified image, showing the best fit for each pixel, subject to a limit specified by the User. Additionally, "rule" images are provided showing the angular distance (in radians) between each spectrum image and each reference spectrum. The black pixels in the "rule" image present low spectral angles values, and therefore more similar to the spectra of endmembers. For best viewing, these images are inverted and the smaller angles appear in a clear tone. 


\section{MEASUREMENTS AND IMAGE PROCESSING}

\subsection{Study area}

The study area is located north of Rio Grande do Sul State, Brazil, City of Ametista do Sul (Figure 1). This region is the greater world amethyst producer. An ASTER image, Level 1B (Figure 2) was used to test and perform the techniques. A total of 16 points of mining residues/basalt was collected via GPS to check the classification/mapping accuracy (Figure 2). The Figure 3(A)(B) shows the mining residues/basalt when it is extracted at the mining process.

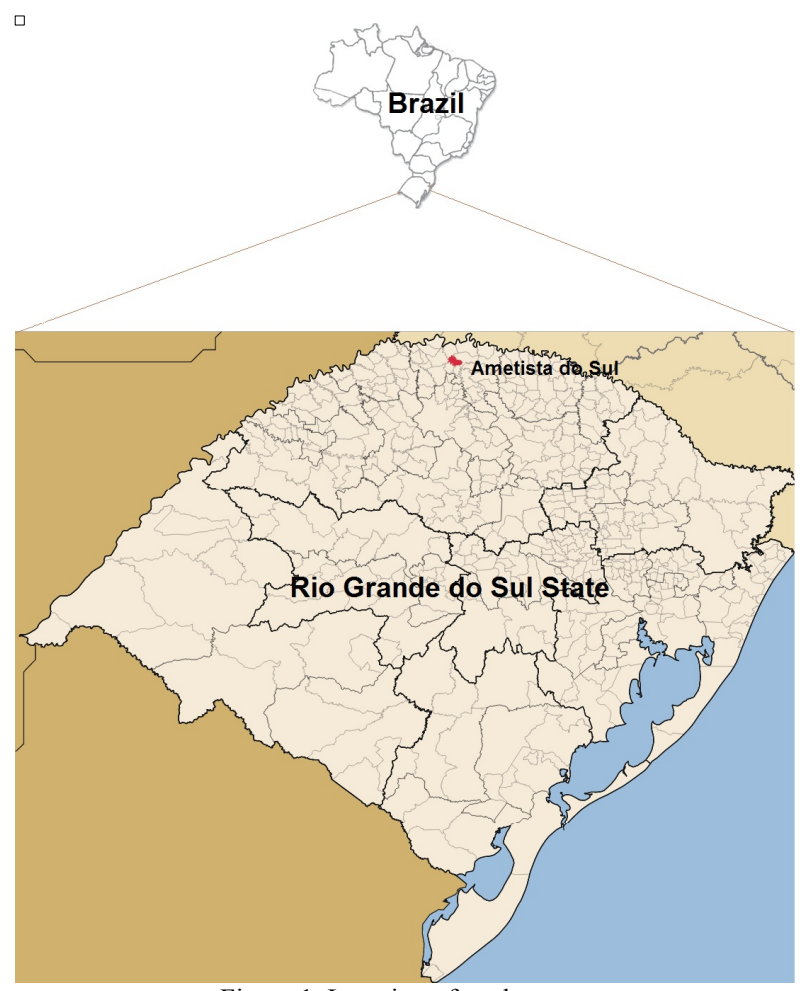

Figure 1. Location of study area.

The basalt is extracted into the mountain during de mining process and deposited outside, where large mounts of rocks are formed (Figure 3). These mounts are many times smaller than ASTER pixel size (VNIR - 15 meters and SWIR 30 meters). Thus, the pixel composition becomes a mixing of various materials, hampering its identification and mapping.

The Figure 2 shows the ASTER scene used to perform the processing. The sixteen mining points collected by GPS are plotted at the scene.

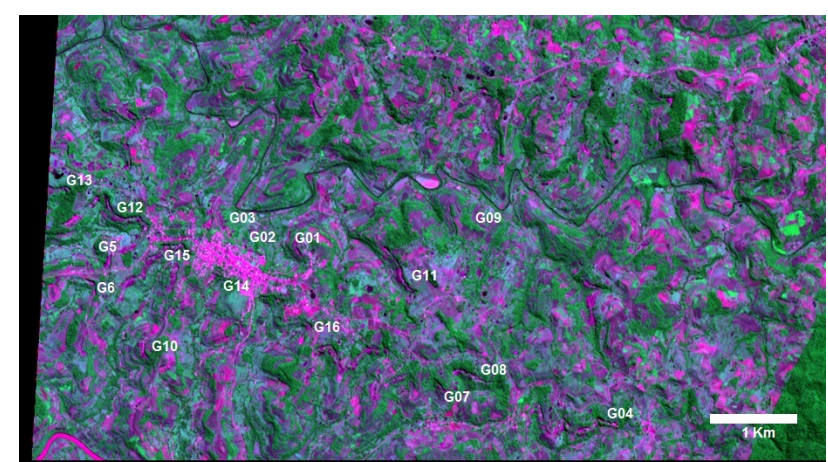

Figure 2. Aster scene color composition R(2), G(3), B(1) with the amethyst mining points distribution.
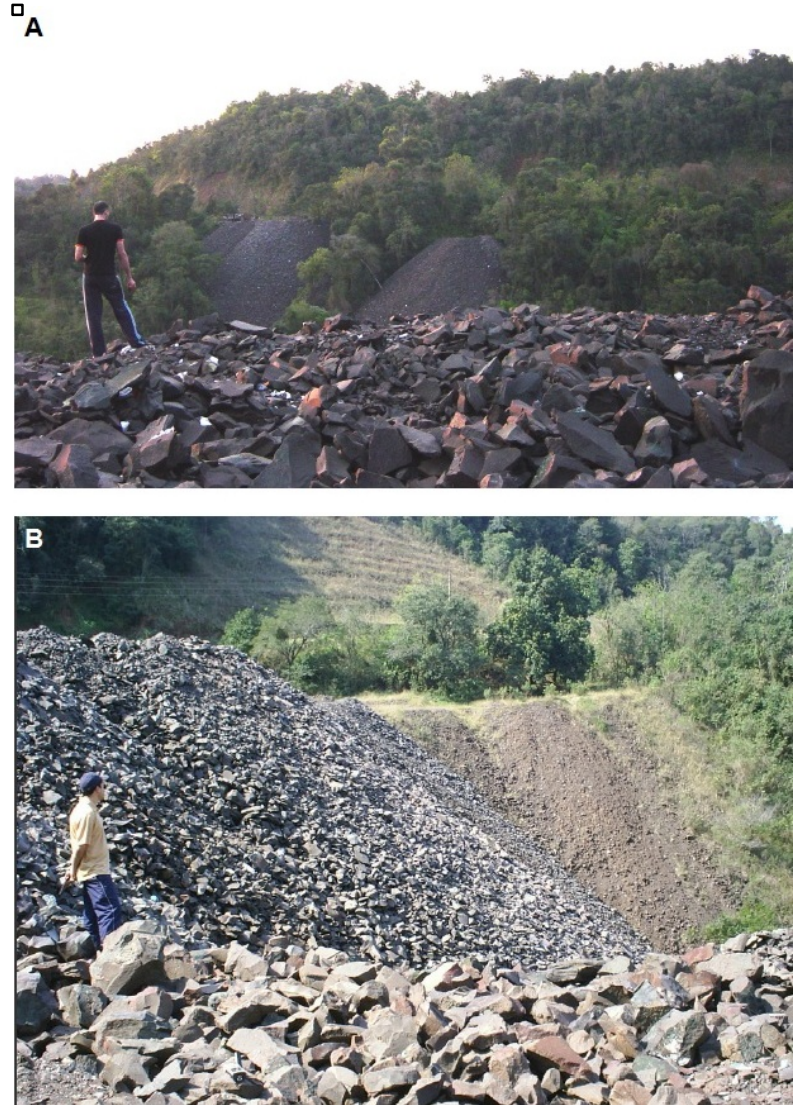

Figura 3. Photographs of amethyst mining residues/basalt.

\subsection{Image Processing}

ASTER Level 1B image was submitted to crosstalk effect correction using the correction software crosstalk (ERSDAC, 2003). This effect affect in ASTER, the dispersion of the incident light in the band 4, which is reflected in the focal plane of SWIR bands, causing, for example, the appearance of "ghosts" at the interface between land and water surfaces (Iwasaki \& Tonooka, 2005). After, the classification was performed using the MaxVer algorithm. We selected six classes: Soil 1, Soil 2, Native forest, Agriculture, Mining residues/basalt and Shadow. The interest classes for this work are Shadow and Mining residues/basalt. The others were used only to improve the classifier accuracy. After the image classified, geometric correction was performed to compare with the mining points collected in field.

The following processes were performed to SAM Technique. The data of original scene ASTER (1B) were converted to apparent reflectance and submitted to atmospheric correction procedures using the Atmospheric Moderate Resolution Radiance and Transmittance Model (MODTRAN), implemented in the application FLAASH (Fast Line-of-sight Atmospheric Analysis of Spectral Hypercube). The following image conditions were considered in the model implemented here: (a) elevation of study region, (b) platform elevation, (c) flight date, (d) aerosol levels (visibility), (e) area coordinates, (f) atmospheric model (tropical).

A spatial re-sampling of SWIR bands was performed, artificially increasing its resolution to $15 \mathrm{~m}$, thus, allowing the composition with Visible bands (VNIR) an image database with 9 spectral bands. From the group of nine bands in reflectance values, we used the following sequence of processes: Technical 
MNF, PPI and N-dimensional viewer. As a result, were extracted mining residues/basalt endmembers used by SAM technique processing.

\section{RESULTS AND DISCUSSIONS}

\subsection{MaxVer processing}

The ASTER image was classified into six classes: Soil 1, Soil 2, Native forest, Agriculture, Mining residues/basalt and Shadow Figure 4 presents the classification results.

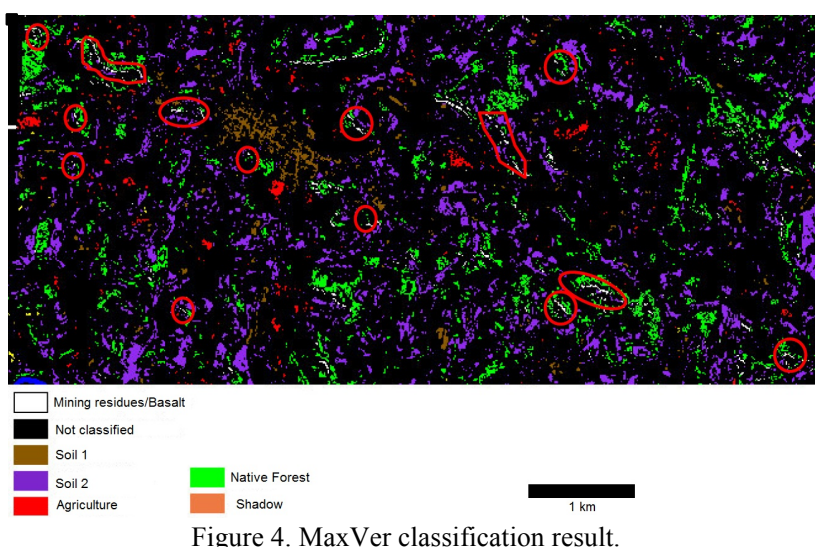

Fourteen of sixteen points mines mapped by GPS were correctly classified by the MaxVer algorithm. The presence of vegetation close the mining residues/basalt is large, especially native forest, hampering the classification, largely caused by shaded areas in the visible region, is easily confused with the mining residues. These two points were not classified, presumably because they were located in very small mines, where the residues mounts are smaller, being strongly influenced by the reflectance of other targets, such as bare soil or shadow. The main problem found with MaxVer algorithm was the mixture produced between the "shadow" and "mining residues/basalt" classes. Several shaded areas were classified as "mining residues/basalt" even when have any occurrence of residues. This can be seen in Figure 5. On the classification result, the "Shadow" class (brown color) included several pixels classified as mining residues/basalt (white color).

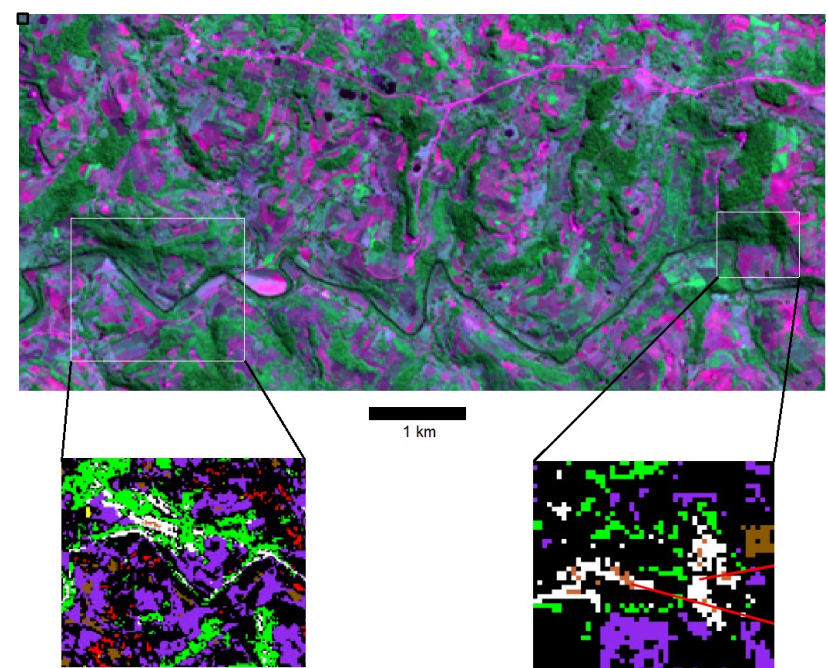

Figure 5. Misclassification between "Shadow" and "Mining residues/basalt" classes. Shadow Pixels were classified like mining residues/basalt (white color).

\subsection{SAM processing}

Figure 6 shows the result of MNF technique. It shows that most of data variance is concentrated in the MNF images 1 to 7 and noise in the last MNF images (8 and 9). In consequence, they were not used as input data in Pixel Purity Index (PPI) technique.

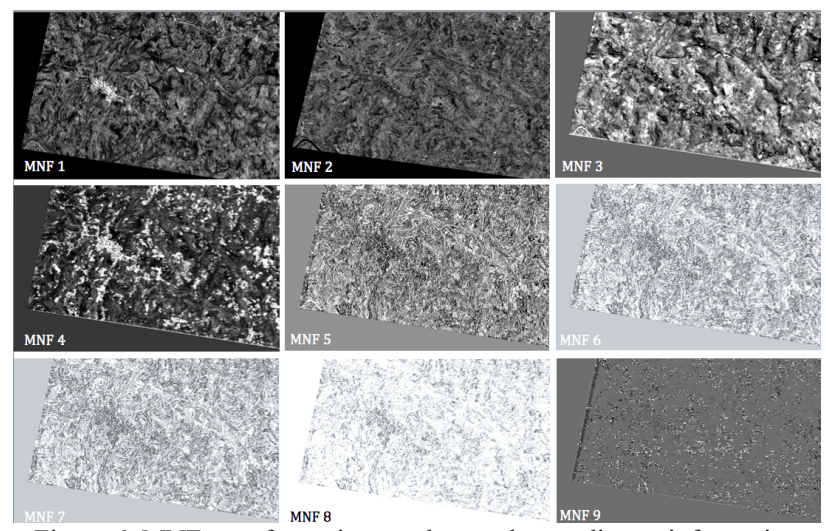

Figure 6. MNF transformation result sorted according to information coherent ;

The PPI technique application result and the subsequent use of the $\mathrm{N}$-dimensional viewer, aimed at the endmembers selection, are illustrated in Figure 7. The purest pixels are found at the extremes of the atributes space, generated by $\mathrm{N}$-dimensional viewer. Through this technique was possible to identify the purest pixels group concerning mining residues/basalt.

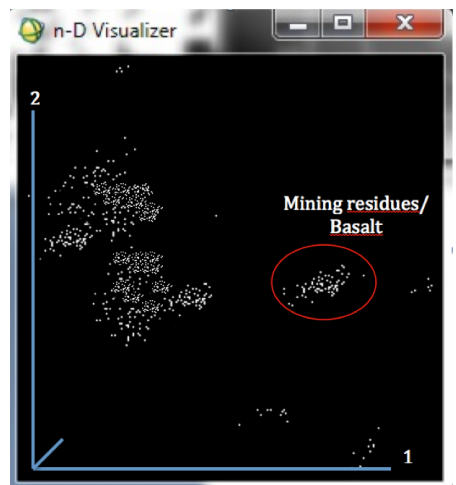

Figure 7. Pixels selected for endmember of the N-dimensional viewer. The projected values are obtained from MNF transformation images.

Figure 8 shows the reflectance spectra, measured by the ASTER sensor, relative to the reference member used in SAM technique, selected by the sequential application of the techniques MNF, PPI and N-dimensional viewer.

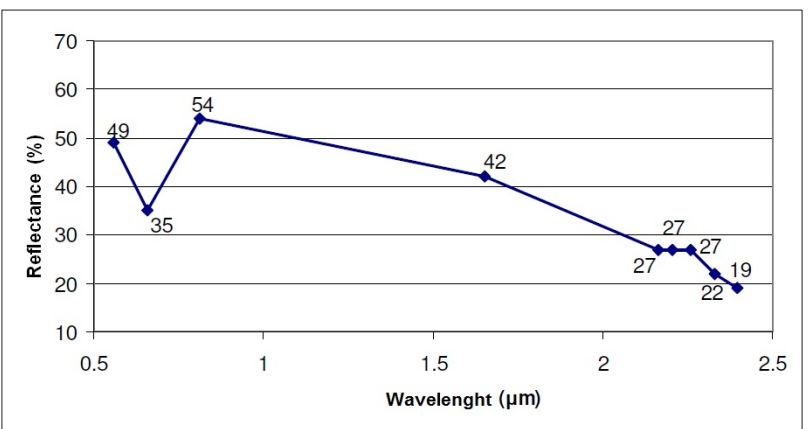

Figure 8. ASTER reflectance spectra to mining residues/basalt endmember. 
As follow, we present the results of SAM technique processing (Figure 9). The lighter pixels are those with greatest similarity with the mining residues/basalt spectral curve, that is, the clearer, more likely to be a pure pixel class.

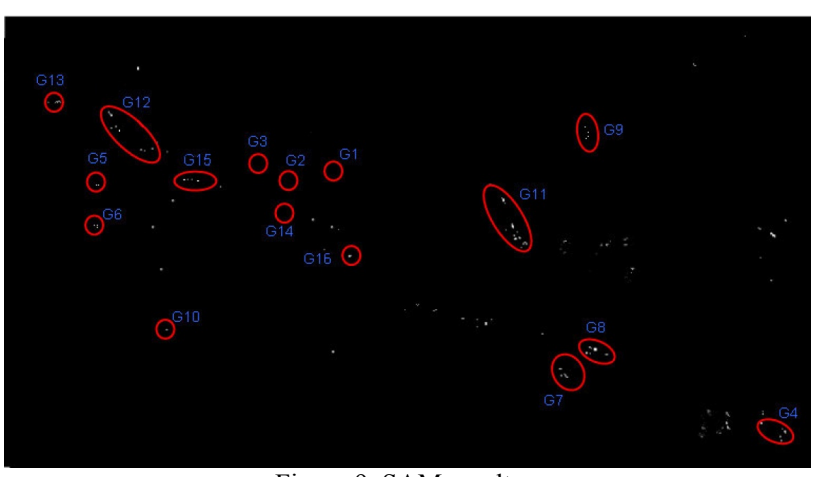

Figure 9. SAM results.

The mining points G1, G2, G3 and G14 did not show similarity with the spectral endmember mainly due to the reduced amount of residues/basalt present at these areas, smaller than one pixel (15 m - VNIR, $30 \mathrm{~m}$ - SWIR). Most of the polygons has pixels with white color saturated indicating the mining residues/basalt occurrence and hence, the mines. The figure also shows other areas identified as "mining residues/basalt" that were not mapped via GPS, indicating the presence of other mines or areas of mixing with shadow. Figure 10 shows the mining residues/basalt points classified by the SAM technique, overlapping in ASTER Band 4.

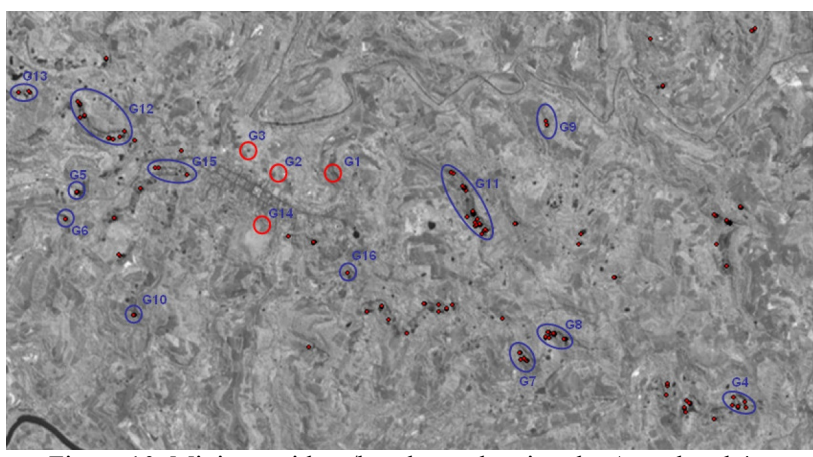

Figure 10. Mining residues/basalt overlapping the Aster band 4.

The advantage using this technique over conventional classification techniques is that it has greater control over the results. Based on the image "rule", we can filter only the pixels with the highest probability of belonging the class under study, whereas in the other classification techniques, the pixels are classified according to a range of values, which are similar.

Classification procedures with reference spectra extracted directly from images to be processed always tend to have better results because factors such as lighting conditions, particles and aerosols, the spectral influence of other targets are already associated with the image and consequently the spectral curve.

\section{CONCLUSIONS}

The results demonstrate that the ASTER images can be very effective for mineral characterization, in the study case, the mining residues/basalt taken from amethysts mining.
The algorithm MaxVer produced satisfactory results. The main problem was the confusion (error) between "shadow" and "mining residues/basalt" classes.

The SAM technique achieved good results and was able to identify the pixels with greater spectral similarity. Even areas where mining residues/basalt occurrence was small, sometimes lower than one pixel, the technique could identify the basalt spectral influence, of course, with a lower similarity value.

The forest native present beside the mines has great influence on the pattern detection process and extraction of spectral reference spectra. Therefore, to generate reference spectra that are more pure and reliable, large areas should be chosen, where the vegetation and shadow influence are smaller.

\section{REFERENCES}

Boardman, J. W., Kruse, F. A., \& Green, R. O. 1995 .Mapping target signatures via partial unmixing of AVIRIS data. In: Summaries, Fifth JPL Airborne Earth Science Workshop, JPL Publication 95-1, 1, 23-26.

Breunig, F. M. Dados de reflectância e emissividade do sensor ASTER/terra aplicados ao estudo de solos quartzosos. 2008. Dissertação de mestrado. INPE.

Carvalho junior, O, A. Carvalho, A.P.F., Meneses, P.R., Guimarães, R. F., Martins, E. S. 2003. Análise de imagens hiperespectrais pelo método Multiple Endmember Spectral misture Analysis (MESMA) em depósito supergênico de níquel. Revista Brasileira de Geociências, v. 33, n.1.

Earth Remote Sensing Data Analysis Center (ERSDAC) 2003. The crostalk correction software user's guide, $21 \mathrm{p}$.

ENVI User's Guide - 3.4 version. 2000. research Systems.

Gao, B. C.; Hiedebrecht, K. B., \& Goetz, A. F. H. 1993. Derivation of scaled surface reflectances from AVIRIS data Remote Sensing of Environment, 44, 165-178.

Green, A. A., Bermam, M., Switzer, P., \& Craig, M. D. 1988. A transformation for ordering multiespectral data in terms of image quality with implications for noise removal. IEEE Transactions on Geosciences and Remote Sensing, 26 (1), 6574.

Iwasaki, A., \& Tonooka, H. 2005. Validation of a crosstalk correction algoritm for ASTER/SIWR. IEEE transactions on Geoscience and Remote Sensing, 43(12): 2747-2751.

Kruse, F. A.; Lefkoff, A. B.; Boardman, J. W.; Heidebrecht, K.B.; Shapiro, A. T.; Barloon, P. J. 2003. The espectral ImageProcessing System (SIPS) - interactive Visualization and Analysis of imaging Spectrometer data. Remote sensing of environment, v.44, n.2-3, p 145-163

Linn, R. M. Avaliação dos Modelos de Mistura espectral MESMA e SMA aplicados aos dados Hiperespectrais Hyperion/EO1 adquiridos na planície costeira do Rio Grande do Sul. 2008. Dissertação de Mestrado. CEPSRM-UFRGS.

Vicente, L. E. 2007. Caracterização de sistemas ambientais tropicais complexos utilizando análise sistêmica e classificação hiperespectral de dados do sensor ASTER (advanced 
ISPRS Annals of the Photogrammetry, Remote Sensing and Spatial Information Sciences, Volume I-7, 2012 XXII ISPRS Congress, 25 August - 01 September 2012, Melbourne, Australia

spaceborne thermal emission and reflection radiometer). Tese de Doutorado, IAG-Unicamp. 